\title{
LA TRANSVERSALIDAD DEL DERECHO A LA ACCESIBILIDAD: AJUSTES RAZONABLES EN EL ÁMBITO LOCAL Y EN LA PARTICIPACIÓN POLÍTICA Y SOCIAL*
}

\author{
MAINSTREAMING IN THE RIGHT OF ACCESSIBILITY: REASONABLE \\ ACCOMMODATION IN THE LOCAL FIELD AS IN THE POLITICAL AND SOCIAL \\ PARTICIPATION
}

\author{
María del Mar Rojas Buendía**
}

\begin{abstract}
RESUMEN: Algunas consideraciones sobre los derechos de las personas con diversidad funcional, tienen que ver hoy con elementos como la accesibilidad y los ajustes razonables en el «espacio local urbano», e invitan a una reflexión filosófica, político-jurídica, y socio-económica conjunta, que guarda relación con el derecho a tener derechos y con su discurso.
\end{abstract}

ABSTRACT: Some considerations on the rights of persons with functional diversity, have to see today with elements such as accessibility and the reasonable adjustments in the «urban local space», and invite a philosophical reflection, political-legal and socio-economic together, which relates to the right to have rights and with its speech.

PALABRAS CLAVE: ciudades, ciudadanía, diversidad funcional, accesibilidad, derechos.

KEY WORDS: cities, citizenship, functional diversity, accessibility, rights.

Fecha de recepción: 14/09/2016

Fecha de aceptación: 22/12/2016

doi: https://doi.org/10.20318/universitas.2017.3560

* Artículo realizado a partir de la Comunicación presentada en el Congreso Internacional «Madrid sin barreras: Accesibilidad, ajustes y apoyos», organizada por el Instituto de Derechos Humanos «Bartolomé de las Casas». Universidad Carlos III de Madrid.

** Doctora en Derecho-Derechos Fundamentales. Instituto de Derechos Humanos «Bartolomé de las Casas»-Universidad Carlos III de Madrid. E-Mail: marojbu@yahoo.es 


\section{1.- INTRODUCCIÓN}

El presente estudio se expresa en los siguientes términos, para concluir con la idea de que el fenómeno de la diversidad funcional genera una ciudadanía pasiva, porque en el proceso de su construcción en democracia no se ha incorporado plenamente a todos los sujetos morales -condicionados por la sociedad y su criterio-, en los asuntos públicos incluidos en la actuación de las autoridades, grupos mediáticos políticos y sociales. Cabe puntualizar sobre los conceptos que arropan este fenómeno para poder anticipar sus consecuencias:

10 la diversidad funcional es un componente vigente $y$ visible en nuestro «modelo social» actual ${ }^{1}$, bajo los auspicios de la Convención Internacional sobre los Derechos de las Personas con Discapacidad, que promueve, protege y asegura el goce pleno y en condiciones de igualdad de todos los derechos humanos y libertades fundamentales por todas las personas con discapacidad, y el respeto de su dignidad inherente ${ }^{2}$;

$2^{\circ}$ la diversidad funcional es una cuestión de derechos humanos $y$, por tanto, ha de seguir abordándose desde su discurso, pues aunque integra las demandas y pretensiones de las personas con discapacidad, sigue existiendo un frente hostil en el discurso político y jurídico, en lo que afecta a su consideración y tratamiento.

Cabe advertir aquí que nos estamos refiriendo a derechos dentro del marco de la técnica jurídica, refiriéndonos a realidades juridificadas, es decir, a instituciones jurídicas.

Tal y como nos recuerda Ansuátegui, « (...) más allá del Ordenamiento jurídico se puede emplear el término 'derecho' (...); con

\footnotetext{
${ }^{1}$ «El siglo XVII fue el siglo de las matemáticas, el XVIII el de las ciencias físicas, el XIX el de la biología. Nuestro siglo XX es el siglo del miedo. Se me dirá que el miedo no es una ciencia. Pero [...] si bien en sí mismo no puede considerarse una ciencia, no hay duda de que sin embargo es una técnica». (A. Camus, Cartas a un amigo alemán, Tusquets, 2007); y, en el siglo XXI «existe mucho desconocimiento e incluso un cierto temor a lo diferente» (R. de Asís Roig, catedrático de Filosofía del Derecho de la Universidad Carlos III de Madrid, en «La satisfacción de la Convención exige un cambio social», Cermi.es semanal-El periódico de la discapacidad-Viernes, 19/02/2016, n. ${ }^{\circ}$ 201. $10^{\circ}$ Aniversario Convención ONU); pero, «(c)uando uno piensa en los demás se da cuenta de que hay que hacer algo (...), y no puedo decir: 'como no puedo hacer nada, no debería hacer nada'. Camus escribió (...) debemos creer que Sísifo era feliz. (...) no puedo creer que Sísifo fuera feliz, pero sí que hay gente que es desdichada. Y (...), no tengo derecho a no tratar de aliviar su desdicha». E. Wiesel, Speak Truth To Power. Defiende los Derechos Humanos, R. F. K. Center, 2013, p. 34.

2 Convención Internacional sobre los Derechos de las Personas con Discapacidad (13/12/2006), Artículo 1.1. Vid., en relación con Principio General de Accesibilidad (Artículo 9); y Ajustes razonables, como concepto transversal para el goce y ejercicio de todos los derechos humanos y libertades fundamentales (Artículo 2). Vid., un estudio detallado de la Convención, en PALACIOS RIZZO, A., El modelo social de discapacidad: orígenes, caracterización y plasmación en la Convención Internacional sobre los Derechos de las Personas con Discapacidad, CERMI-CINCA, 2008.
} 
una importante carga semántica en el discurso político o moral. Pero los individuos sólo tienen derechos fundamentales cuando en un Ordenamiento jurídico (...) existen 'normas de derechos fundamentales', que satisfacen los criterios de validez formal y material de ese Ordenamiento ${ }^{3}$, y que atribuyen capacidades, prerrogativas 0 facultades, en forma de derecho subjetivo, libertad, potestad o inmunidad» ${ }^{4} ; y$, por último,

30 lo antedicho conlleva atender todos los elementos del discurso de los derechos y, en un ejercicio de aceptación y adaptación, incluir la diversidad funcional y a las personas (físicas y/o jurídicas) representativas de éstas, dentro del «espacio público de discusión y decisión», como sujetos morales con autonomía moral ${ }^{5}$, capaces de consensuar sobre aquello que les afecta (en detrimento del obsoleto discurso de la discapacidad o cuanto menos de forma adaptada al discurso de los derechos ${ }^{6}$ ), en condiciones de igualdad (desde el punto de vista filosófico y en el marco público de moralidad que aquí manejamos conceptualmente, previo al ámbito jurídico donde los derechos son realidades normativas existentes y válidas).

Un contexto de ética pública asumida, no creada inicialmente, por un poder político; que se convierte en ética jurídica positivizada, al entrar en las formas de producción normativa, y a través del legislador y después del juez adquiere una dimensión de construcción, que se identifica con los instrumentos de que dispone el Derecho para producir las normas. «Así, la ética pública dada se

3 Vid. CUENCA GÓMEZ, P., «La concepción del Ordenamiento jurídico de Norberto Bobbio», Papeles el tiempo de los derechos (Huri-Age. Consolider-Ingenio. 2010), no 2, Año: 2010; donde se argumenta que Bobbio, como clarificador del significado de la estructura jerárquica del Ordenamiento, «siempre asumió la teoría kelseniana (superando su aproximación) de la elaboración gradual del Ordenamiento jurídico, que reconstruye la unidad a través del principio de jerarquía normativa», p. 3 (la cursiva es mia). Cuenca, citando a Bobbio, dirá que el rasgo significativo del positivismo jurídico contemporáneo (modelo que fundamenta el presente estudio. La cursiva es mía) frente al positivismo tradicional es la afinidad de aquél con el punto de vista del Ordenamiento en su conjunto, frente a la fuerza fundamental sobre el punto de vista de la norma, «aquello que nosotros denominamos generalmente Derecho es una característica de ciertos ordenamientos normativos más que de ciertas normas», vid. BOBBIO, N., Teoría General del Derecho, Debate, Madrid, 1991, p. 173; KELSEN, H., Teoría pura del derecho, trad. de R. Vernengo, Porruá, Buenos Aires, 7.a ed., p. 215, también KELSEN, H., Teoría General del Derecho y del Estado, trad. de E. García Maynez, UNAM, México, 1995, p. 146.

${ }^{4}$ Vid. ANSUÁTEGUI ROIG, F. J., Poder, Ordenamiento Jurídico, Derechos, Cuadernos "Bartolomé de las Casas", núm. 2, Universidad Carlos III de Madrid-Dykinson, 1997, pp. 2 y 3.

5 HABERMAS, J., Facticidad y validez, trad. M. Jiménez Redondo, Ed. Trotta, Madrid, 1998, pp. 149 y ss.

6 DE ASÍS ROIG, R., «Sobre la accesibilidad universal», Papeles el tiempo de los derechos (Huri-Age. Consolider-Ingenio. 2010), no 4, Año: 2013, p. 1. 
convierte en ética pública construida. (...), parte de los valores básicos dados, (...), y del espacio público en que se realiza con unos ciudadanos en igual posición de ciudadanía, (...). La realización de esa construcción tiene que ser visible, con publicidad en los procedimientos y en los debates ${ }^{7}$.

A efectos de su participación pólitico-jurídica e inclusión socio-económica en calidad de ciudadanas/os, en la creación de los «nuevos escenarios y espacios» ${ }^{8}$ pensados para sus ciudades. Con determinados servicios de apoyo, ajustes y normas relacionadas, para normalizar su vida en la ciudad.

Concluimos pues con la idea fundamentadora de este estudio, que arranca de un modelo que maneja dos exigencias: por un lado, la justificación ética $y$, por otro, la incorporación de cualquier pretensión al Derecho; para poder hablar del derecho a tener derechos dentro del contexto que aquí nos preocupa, el de la «diversidad funcional» ${ }^{9}$.

\section{2.- GLOBALIZACIÓN EXCLUYENTE E INCLUSIVA}

Expresiones como «globalización» forman parte del bagaje de un metalenguaje ideologizado que, sin embargo, no merma la impresión de que aquel concepto se esté diseñando como un «medio excluyente». La gran paradoja de este fenómeno radica en que nunca antes había existido un mayor reconocimiento de los derechos humanos, de los derechos universales; $y$, sin embargo, nunca antes tantos sectores poblacionales se habían visto tan privados de los mismos como ahora ${ }^{10}$, entre estos sectores, el de la diversidad funcional.

7 (La cursiva es mía). Vid. PECES-BARBA MARTÍnEZ, G., «Ética Pública y Ética Privada», Cita en TAMAYO, J. J. (dir.). «Aportación de las religiones a una ética universal». Instituto de Derechos Humanos Bartolomé de las Casas, Dykinson, Madrid, 2003, p. 22; también sobre la distinción entre ética pública y ética privada, del primer autor: Ética, Poder y Derecho. Reflexiones ante el fin de siglo, Centro de Estudios Constitucionales, Madrid, 1995.

8 TOCA, G., «Retos de las Smart Cities», Entrevista a Antoine Picón («La ciudad se enfrenta constantemente a circunstancias imprevistas»), Spotlight On: Smart cities, en «Ideas. IE Alumni Magazine» (Spring-Primavera 2016), p. 15, disponible en http://www.ideas.ie.edu (consulta: 03/2016).

9 «El modelo dualista se caracteriza por manejar ambas exigencias. (...) Esto significa que: a) sin justificación moral no hay derecho fundamental $y, b$ ) sin incorporación al Derecho no hay derecho fundamental», vid. DE ASÍS ROIG, R., Sobre el concepto y el fundamento de los derechos: una aproximación dualista, Cuadernos «Bartolomé de las Casas», n.0 17, Universidad Carlos III de Madrid-Dykinson, 2001, p. 17.

10 ALGUACIL GÓMEZ, J., «El desarrollo social hoy: caminando hacia el desarrollo humano sostenible», Documento de trabajo para la elaboración del capítulo 1: «La visión del desarrollo social en el siglo XXI», versión electrónica en VI Informe sobre 
La exclusión nos remite (desde un punto de vista sociológico que no descuida la perspectiva jurídica y tampoco la política), dentro de la esfera local, a los procesos de urbanización, donde a la polarización delimitada por la dimensión económica que determina diferentes niveles de vida, en el caso del colectivo con diversidad funcional, se le suma la separación de oportunidades vitales (o segmentación) en la que cabe tanto la «oportunidad de participación social y política» como la lejanía de las «oportunidades de trabajo y ocio».

Nos sirve el ejemplo del incremento de segregación y exclusión, y la negación de oportunidades a las que tienen derecho las personas con discapacidad que son objeto de muchos de los proyectos de desarrollo que prevén la construcción de escuelas y de centros de formación profesional, la creación de sistemas de transporte público o la apertura de nuevas fábricas, talleres y oficinas; y que en su planificación no han integrado las necesidades particulares de estas personas con discapacidades. O'REILLY habla de que «la experiencia en otros ámbitos demuestra claramente que intentar que los edificios ya construidos sean accesibles para las personas con diferentes discapacidades es a la vez difícil y costoso. Por lo tanto, debería prestarse atención a los requisitos de accesibilidad desde las fases iniciales de la construcción ${ }^{11}$. Y añade que «(e)I sistema de los Documentos de Estrategia de Lucha contra la Pobreza en los países de bajos ingresos, que lanzaron el Fondo Monetario Internacional y el Banco Mundial debe revisarse para asegurarse de que se tiene debidamente en cuenta las necesidades de las personas con discapacidades que viven en la pobreza» ${ }^{12}$.

Por esta razón cabe traer a colación de esta idea que, en el año 2012, el Secretario General de las Naciones Unidas, comenzó a llevar a cabo varias iniciativas dentro del marco del Desarrollo sostenible, como el establecimiento de un Grupo de Trabajo sobre la Agenda de Desarrollo Post-2015, uno de cuyos objetivos (Objetivo n. ${ }^{\circ} 11$ ) consista en: «Lograr que las ciudades sean inclusivas y seguras», consistente en viviendas y servicios básicos adecuados y asequibles; mejora de los barrios marginales; sistemas de transporte seguros; reducción del número de muertes por desastres; y el acceso universal a zonas ${ }^{13}$.

La accesibilidad y los ajustes razonables como elementos transversales a los demás derechos de las personas con diversidad funcional, y a su disfrute, exigen actualmente no sólo la eliminación de

exclusión y desarrollo social en España 2008, FOESSA, disponible en: http://www.foessa.es/publicaciones_download.aspx?Id=3845 (consulta: 02/2016).

${ }^{11}$ Vid. O'REILLY, «El derecho al trabajo decente de las personas con discapacidades», Oficina Internacional del Trabajo, Ginebra, 2007, p. 141, disponible en: http://www.ilo.org/publns (consulta: 04/2016).

12 «El derecho al trabajo decente...», op. cit., p. 141.

13 http://www.un.org/es/development/desa/development-beyond-2015.html 
barreras arquitectónicas y humanas, sino un diseño universal para todos, centrado en el ser humano, para mejorar la «autonomía personal» de este colectivo; puesto que, «en el marco de la discapacidad, el concepto de barrera es un concepto amplio que abarca obstáculos físicos, ambientales, culturales, psicológicos o cognitivos» ${ }^{14}$ y, además «varía en relación con situaciones y sujetos» ${ }^{15}$.

En nuestro caso, la planificación de las ciudades, la gestión de sus entornos y servicios ${ }^{16}$; y el diseño de las ventajas y los servicios de las Tecnologías de la Información y la Comunicación (TIC) que se pueden llegar a facilitar a los ciudadanos, deben realizarse teniendo en cuenta estos principios (accesibilidad universal y diseño para todos), acercando tanto la utilización de las aplicaciones como los servicios a los que se puede acceder.

Si nos guiamos por un estudio realizado en España por el Centro de Innovación del Sector Público de PwC y el IE Business School en colaboración con Telefónica, descubrimos que «ocho de cada diez (ciudadanos) españoles afirman conocer el concepto de ciudad inteligente. Dos de cada diez considera su ciudad inteligente o muy inteligente y que la Administración Pública debe liderar la transformación digital. Los ámbitos que más les preocupan son sanidad, medioambiente, educación y seguridad; y estarían dispuestos a pagar por teleasistencia, educación abierta y programas de salud» ${ }^{17}$.

En cuanto a las ciudades, se apuesta por una hoja de ruta para lograr: 1) el «liderazgo y cambio organizativo a un modelo transversal»; 2) «preparar un plan de ciudad»; 3) la «evolución del marco legal» ${ }^{18}$; 4) un «modelo tecnológico open source, open data e interoperabilidad de plataformas»; 5) una «financiación pública y privada»; y, 6) «modelos de negocio sostenibles» ${ }^{19}$.

Mas, para que se puedan catalogar las ciudades como inteligentes, las acciones llevadas a cabo en ellas deben incluir la accesibilidad en un

\footnotetext{
14 «Sobre la accesibilidad universal», op. cit., p. 2.

${ }^{15}$ Vid. Ibídem.

16 Planificación eficaz: Desarrollo de Uso Mixto. En definitiva, una combinación de cooperación residencial, influencia política y vitalidad económica; vid., JACOBS, J., The Death and Life of Great American Cities", Random House-Nueva York, feb-1993 (1.a edic.: 1961).

17 Vid. «Libro Blanco de Smart Cities. La transformación digital de las ciudades»: estudio que apunta a un «proceso de urbanización» más una «revolución digital/industrial 4.0», que dará lugar a una sociedad colaborativa. «En 2020 , el $60 \%$ de la población española será urbana» y, además, «habrá 50.000 millones de dispositivos conectados en el mundo»; en Spotlight On: Smart cities..., op. cit., p. 18.

18 Vid. «Las Normas para las Ciudades Inteligentes. Informe de situación», Asociación Española de Normalización y Certificación - AENOR, octubre de 2015, pp. 5-18.

19 «Libro Blanco de Smart Cities...», op. cit., p. 18.
} 
sentido amplio, además de la concienciación por parte de las Administraciones y el resto de la ciudadanía.

Esto conlleva tener también en cuenta el concepto de ciudades y entornos inteligentes desde la percepción que tienen las/os propias/os ciudadanas/os, caracterizadas por: 1) su accesibilidad arquitectónica y humana; 2) el respeto al medio ambiente; 3) la movilidad (transporte); 4) unos servicios públicos de calidad; y, 4) una comunicación e información accesibles.

Y, además, por el concepto ofrecido por las/os expertas/os como: 1) complejo, anticipado al futuro; 2) con objetivos de desarrollar las mejores condiciones de calidad de vida y bienestar de todas las personas en su contexto social; 3) como ecosistema en el que interactúan aspectos físicos (diseño y arquitectura), estructuras socioeconómicas y otros procesos vitales (multiculturalismo, diversidad, etcétera);4) que incluye políticas y medidas, e introduce las TIC; 5) no se limita a un lugar determinado, la persona es el centro: comprende lo que se refiere a ella, «a todos» (el entorno urbano, el transporte, el lugar de trabajo, etcétera); reconoce y responde a su presencia y necesidades diferentes de forma discreta e imperceptible; 6) «sin barreras»: con aplicaciones para los usuarios y diversos terminales y dispositivos accesibles ${ }^{20}$.

El diseño y construcción de ciudades inclusivas y accesibles no implica sólo su adecuación para personas con limitaciones físicas, sino también para otro tipo de personas como niños, embarazadas o personas mayores; que hace de este tipo de ciudades, un espacio visible por todos los ciudadanos. El concepto de adecuación general ha de entenderse desde la suma de cuatro perspectivas:

1. La inclusión social, que proporciona a todos los ciudadanos, sin establecer discriminación alguna por razón de raza, origen étnico, condición, género o estatus socioeconómico, una vivienda adecuada, servicios básicos y un acceso igualitario a los servicios sociales y otros bienes públicos esenciales para el bienestar general y ambiental de todos.

2. La inclusión económica, que proporciona a sus ciudadanos igualdad de oportunidades para los negocios y acceso al empleo, fomentando políticas económicas a favor de los grupos vulnerables (personas con discapacidad, inmigrantes, etcétera).

3. La inclusión política, que respeta y defiende los derechos y libertades de sus ciudadanos y fomenta la participación social y política, para una mejor toma de decisiones por parte de sus dirigentes de forma democrática.

${ }^{20}$ Vid. Informe «Entornos Inteligentes, Accesibles y Amigables», CEAPAT, 2013; vid. "Ideas. IE...", op. cit. 
4. La inclusión cultural, que favorece la inclusión social y la diversidad, y valora los derechos culturales de forma plural fomentando el arte y el patrimonio.

Podemos decir que «una ciudad inclusiva es una ciudad amigable, y una ciudad amigable es una ciudad diseñada para todas las edades y todas las capacidades» ${ }^{21}$. La ciudad es un espacio que debe ser visible por todos los ciudadanos.

Los entornos inteligentes para la vida, como los elementos de apoyo y todos los servicios deben caracterizarse por su «diseño útil», que ha de ser universal, seguro, saludable, funcional, comprensible y atractivo para todos; además de diverso, centrado en las personas, en su seguridad, accesibilidad y necesidades ${ }^{22}$.

\section{3.- LA PARTICIPACIÓN PÚBLICA DE LA DIVERSIDAD}

Las personas con discapacidad tienen «derecho a participar en la dirección de los asuntos públicos». Éste es un concepto amplio que comprende todos los aspectos de la Administración pública y la elaboración de políticas, y guarda relación con el ejercicio del poder político (poder legislativo, ejecutivo y administrativo); abarcando, además, la participación en debates y diálogos públicos, en manifestaciones y reuniones pacíficas ${ }^{\mathbf{2 3}}$.

La participación puede ser directa o indirecta. La participación directa supone decidir sobre cuestiones públicas a través de un referendo o de otro proceso electoral, además de poder participar en asambleas populares y en otros espacios de consulta establecidos por el Estado para interactuar con los ciudadanos. La participación indirecta puede ejercerse mediante la votación libre para elegir a representantes y la adhesión a organizaciones de la sociedad civil, que comprenden a una amplia gama de organizaciones voluntarias y no estatales, asociaciones, redes y grupos formados por personas en la esfera social de la sociedad civil e incluyen a las organizaciones que representan a personas con discapacidad. Debe garantizarse la participación tanto de los particulares como de las agrupaciones ${ }^{24}$. Más allá del ámbito de los derechos políticos, la Convención Internacional sobre los Derechos de las Personas con Discapacidad asegura la posibilidad de expresar, por parte de éstas, su opinión en todos los asuntos que les afectan.

21 «Libro Blanco. Ciudad inclusiva», Fundación ONCE - TECNALIA, 2015, p. 12. Disponible en: http://www.plataformaptec.es (consulta: 07/2016).

${ }^{22}$ Vid. «Libro Blanco. Ciudad inclusiva», op. cit., p. 3.

${ }^{23}$ AGNU, 12 de enero de 2016. A/HRC/31/62: «Informe de la Relatora Especial sobre los derechos de las personas con discapacidad».

${ }^{24}$ AGNU. A/HRC/31/62: «Informe de la Relatora Especial...», op. cit. 
Hay que tener en cuenta que la ciudadanía es sinónimo de «participación en la vida pública» y ser ciudadano consiste en ser «sujeto de derechos y deberes» garantizados por el Estado. Esto es, reivindicar «los derechos» como base fundamental en los distintos organigramas y políticas urbanas ${ }^{25}$. Sin embargo para convertirse en asuntos públicos, las cuestiones a problemas tienen que identificarse empíricamente y dimensionarse cuantitativamente; explicarse mediante algún esquema lógico conceptual; interpretarse; analizarse desde el punto de vista de la opinión pública ${ }^{26}$.

Por ello, es cierto que la comunicación y la información han de formar parte de toda acción colectiva. En este caso, si que puede decirse que toda fundamentación de los derechos necesita expresarse, para cumplir sus verdaderos fines, y que toda justificación tiene las pretensiones de la universalidad que necesariamente la comunicación otorga ${ }^{27}$. Las tecnologías abren esta posibilidad, la de una comunicación universal, pero a la vez estos nuevos sistemas y métodos de comunicación entrañan un peligro: son un factor de poder que, al concentrarse, contribuyen a la desigualdad social, que debe corregirse; pues lo deseable es que estos sistemas contribuyan a una integración sociall $^{28}$, con idéntico poder en la discusión entre todos los agentes morales o individuos participantes.

Los participantes han de hallarse todos en una posición de igualdad simétrica $y$, por tanto, no debe existir entre ellos relación alguna de superioridad o de subordinación que pueda condicionar su libertad de acción. Asegurada la plena libertad de los participantes, sin coacción, el discurso se orienta exclusivamente a la búsqueda cooperativa de la verdad. En el discurso se manifiestan el pragmatismo y la racionalidad de los sujetos a la hora de alcanzar entre sí un acuerdo. La coacción elimina la libertad y la igualdad de los participantes (al menos parcialmente) en la acción comunicativa, imposibilitando un acuerdo racionalmente motivado ${ }^{29}$.

El discurso de la acción comunicativa consiste en una conversación organizada, coordinada y racionalmente disputada, argumentada desde distintas opiniones, con el objetivo de consensuar sobre una «normativa con pretensiones de validez» centrada en razones mutuamente aceptables. Esta forma racional de conversar, «como

\footnotetext{
${ }^{25}$ Vid. «Libro Blanco. Ciudad inclusiva», op. cit., p. 14.

${ }^{26}$ Vid., Facticidad y validez, op. cit., p. 375.

${ }^{27}$ DE ASÍS ROIG, R., Sobre el concepto y el fundamento de los derechos..., op. cit., p. 52.

28 HABERMAS, J., Theorie des kommunikativen Handelns I, Frankfurt am Main: Suhrkamp Verlag, 1985, pp. 46-48.

29 «...jeden (sei es von aussen auf den Verständigungsprozess einwirkenden oder aus inm selbst hervorgehenden) Zwang -ausser dem des besseren Argumentes-...», Theorie des kommunikativen, op. cit., p. 48.
} 
proceso es una forma de comunicación que ha de aproximarse suficientemente a condiciones ideales» ${ }^{30}$.

La ciudadanía en términos globales representa el globo terrestre ${ }^{31}$, la expectativa es que la globalización se haga en términos de ciudadanía, entendida como técnica de ejercicio de la democracia. Y que el espacio público de discusión y decisión sirva para proyectar posibles planes de vida aceptables en la sociedad (a partir de la libertad de elección y sus exigencias ${ }^{32}$ ).

De hecho, poder exponer e investigar casos de buenas prácticas que aporten conocimiento y experiencia a otras ciudades para el diseño e implementación de sus políticas de inclusión social ${ }^{33}$.

Por otra parte, en cuanto al reflejo de los derechos humanos en las instituciones internas del Estado. A este respecto, cabe precisar que sigue siendo necesario resituar el concepto de ciudad, dentro del marco que se elige para aplicar la teoría jurídica, al margen de su racionalización y fuera del estrecho ámbito de un solo espacio, puesto que éste es un contexto donde cada vez se juega menos la organización de la convivencia pública.

El concepto de ciudad está cambiando en este nuevo contexto de fuerte crecimiento de la población urbana: «ciudad» tenderá a ser cada vez más «región». Una ciudad grande, extensa territorialmente, con un tamaño que garantice la capacidad competitiva de su base económica. «Nuevas ciudades-territorio donde la movilidad de sus habitantes será alta y flexible, es decir, trabajo, residencia, networking, ocio y estudio se combinarán en diferentes zonas, barrios, municipios ${ }^{34}$.

El espacio político es aquí, concreción de la técnica ciudadana, ejercicio de la democracia o el uso de medios políticos (jurídicos,

30 «Als Prozess betrachtet, handelt es sich um eine unwahrscheinliche, weil idealen Bedingungen hinreichend angenäherte Form der Kommunikation», vid. Ibídem, p. 47; «habe ich versucht, die allgemeinen kommunikativen Voraussetzungen der Argumentation als Bestimmungen einer idealen Sprechsituation anzugeben» (Ibid., p. 46).

${ }^{31}$ Vid. "El desarrollo social hoy...", op. cit., p. 24.

32 Vid., Sobre el concepto y el fundamento de los derechos..., op. cit., pp. 52-56.

33 El «Observatorio Ciudades Inclusivas» es una plataforma de análisis y reflexión sobre políticas locales de inclusión social, que ha puesto en marcha la «Comisión de Inclusión Social, Democracia Participativa y Derechos Humanos de la Red Mundial de Ciudades y Gobiernos Locales y Regionales» (United Cities and Local Governments). Actualmente cuenta con sesenta estudios (desarrollados por la University College of London y un equipo de investigadores del Centro de Estudios Sociales (CES) de la Universidad de Coimbra) acerca de políticas innovadoras sobre desarrollo comunitario, acceso a los servicios básicos, igualdad de género, protección del medio ambiente o erradicación de la pobreza, etcétera. Disponible en: http://www.uclgcisdp.org/es/home (consulta: 07/2016).

${ }^{34}$ Vid. FRIGOLA, R., «Claves para entender las smart cities», en Spotlight On: Smart cities..., op. cit., p. 9. 
institucionales, sociales, personales y económicos), con una finalidad: su autogobierno.

La sociedad siempre camina un paso por delante de la ley (o dos), la sociología es una herramienta de análisis que encuentra su propia forma empírica de actuación. Si nos centramos en lo que el concepto accesibilidad de la diversidad funcional nos ofrece, a la hora de afirmar procesos conscientes de socialización (facilitando experiencias organizativas que articulen diferentes expectativas, otorguen identidad a los grupos y ofrezcan espacios y actividades integradoras), la transformación del rostro de las ciudades en el mundo, y particularmente de España, encontrará su vertiente positiva: los sujetos afectados pueden ser los artífices de sus propias transformaciones.

Las ciudades tienen la capacidad de ofrecer algo a todos, solo porque, y solo cuando, son creadas por todos ${ }^{35}$. Para ello se necesita tiempo, espacio, medios; $y$, apertura a las diferentes realidades.

Para concluir, añadir que el conocimiento no deja de ser una construcción jurídica y también social, y el conflicto referido a los conceptos inclusivo y excluyente, manifiesto hoy en la articulación, generación y asimilación de los diferentes conocimientos enfocados a la diversidad, debe resolverse desde la complementariedad entre ellos, mediante su inclusión a través de la accesibilidad y la participación, que sugiere que el sujeto moral es capaz de formar parte de un espacio público de discusión y decisión, y de actuar.

\section{4.- CONCLUSIONES}

1. El problema de contar con una ciudadanía pasiva en nuestras ciudades se remite entre otros, también al fenómeno de la diversidad funcional.

2. El proceso de construcción de la ciudadanía unido a la consolidación del Estado de Derecho se basa en un modelo político de democracia representativa que no ha incorporado plenamente a todos los sujetos morales, condicionados por la propia sociedad y sus criterios, en los asuntos públicos.

3. La participación en la comunicación, que permite aportar propuestas sobre las necesidades y pretensiones, además de las obligaciones; y poder cuestionarlas en el discurso, es una participación desigual del sujeto moral en el discurso público que concierne a la comunidad.

4. La democracia participativa se sustenta en nuevas bases de la intervención pública que permite el encuentro con los ciudadanos. Sólo es posible en el marco de los derechos humanos.

${ }^{35}$ Vid., The Death and Life of Great American Cities, op. cit. 
María del Mar Rojas Buendía - La transversalidad del derecho a la accesibilidad...

5. En la dinámica de cambiar la sociedad, es imprescindible analizar los fallos diseñando un nuevo modelo social, alcanzable mediante su transformación. Se trata de situaciones que necesitan ser convertidas en asuntos públicos y, por tanto, incluidos en la actuación de las autoridades, grupos mediáticos políticos y sociales. 